\title{
Analysis of the Benefits of Applying Genetic Engineering to the Crop Industry Based on Economics and Efficiency
}

\author{
Do Hoon Kim \\ Northfield Mount Hermon, One Lamplighter Way, Mount Hermon, MA 01354, USA; dkim21@nmhschool.org
}

ABSTRACT: This study evaluates the agricultural benefits accrued from genetically modified crop production (GMCs), developed from genetic manipulation technology, in terms of economics and efficiency. The parameters assessed include yield, cost savings, and reduction in management time through GMC use; additionally, quantitative exploration of the extent of improvement in these parameters was conducted. The results show that GMCs lead to a clear improvement in yield, reduces the cost per unit area, and reduces crop management time.

KEYWORDS: Plant Sciences; Agriculture; Genetically Modified Crop (GMC); Yield; Cost Savings.

\section{- Introduction}

A genetically modified organism (GMO) is an organism whose gene structure has been altered by genetic engineering techniques. These techniques usually refer to methods that cannot be achieved through natural mating or recombination. Genetic manipulation is being actively studied, regardless of organism type. Through genetic manipulation, it is possible to cross genes within the same species, between different species and kingdoms.

Genetic modification is the most commercialized in crops. Genetically modified crops (GMCs) can be immune to certain pests or herbicides and can be made to be spoilage resistant. ${ }^{1}$ Improvements in nutrient content can also be achieved (e.g., golden rice, which contains more vitamin A than normal rice). ${ }^{2}$

There is not much information on how GMCs have benefited farmers economically and in terms of efficiency. ${ }^{3,4}$ This study seeks to provide a more detailed analysis of the advantages of GMCs. GMCs have a considerable effect on farmers and the crop industry. ${ }^{5}$ A quantitative analysis of $\mathrm{GMCs}$ enables farmers to predict industry trends and calculate benefits they can obtain from genetic engineering. It will also be of interest to investors and other stakeholders looking to invest in the GMO industry.

The objective of this study is to analyze quantitatively how GMCs affect the industry. Currently, genetic engineering techniques are the most often applied in soybean, corn, and cotton production. ${ }^{6}$ Analysis of these crops will make the benefits of applying the same genetic engineering techniques available for extrapolation to other crops. The study addresses the following questions:

1. To what extent do GMCs improve yield?

2. By how much does GMCS reduce costs?

3. How much management time is saved by GMC use?

To answer these questions, linear regression will be used to determine the yield and GMC percentage relationship. This relationship will reveal whether there is an improvement in yield. Next, GMC and non-GMC consumption costs will be calculated and compared to determine cost improvement. Finally, the management time saved will be estimated using the herbicide requirement of the crops.

\section{- Methods}

\section{Literature Review:}

In the past, the existence of genes was not known, but breeding was carried out by obtaining the offspring of organisms with desired traits, selecting some of them and crossing them again. Owing to the development of genetic engineering, a more direct approach is possible, ${ }^{7}$ unlike breeding, which depends somewhat on chance.

GMCs can be divided into two categories: transgenic or cisgenic. Cisgenesis refers to the genetic modification of two species that can cross in nature. The difference between breeding and cisgenesis is that breeding relies on the probability that the desired genes will interact, but the cisgenic method can derive results quickly by insertion of the required desired genes. Transgenic is the genetic modification of two species that cannot be crossed in nature. The gene inserted into the crop may be of animal or bacterial origin.

\section{Sample Selection}

\section{Type of Crops:}

The growing areas shown in Table 1 indicate that in 2014 corn, soybean, and cotton were the most cultivated GMCs; their data will be used in the present study.

\section{Modified traitss:}

The modified traits shown in Table 2 will be used in the present study as they are the most common traits.

\section{Statistical Method:}

Crop yield was modeled using linear regression determined by the following equation, where $\mathrm{x}$ is the percentage of GMCs and $y$ is the yield:

$$
Y=a X+b
$$

To evaluate the relationship between the yield and the percentage of GMC, the correlation coefficient ( $r$ ), slope of linear 
regression (a), and coefficient of determination $\left(\mathrm{R}^{2}\right)$ were calculated. The following equation shows how $\mathrm{r}$ was calculated:

$$
r=\frac{\sum\left(x_{i}-\bar{x}\right)\left(y_{i}-\bar{y}\right)}{\sqrt{\sum\left(x_{i}-\bar{x}\right)^{2}} \sqrt{\sum\left(y_{i}-\bar{y}\right)^{2}}}
$$

Source: 1995-2000 data, Fernandez-Cornejo (2000) based on USDA data; 2001-2018 data, U.S. Department of Agriculture (USDA), Economic Research Service (ERS)

Table 1: This is the table of the planted areas of genetically modified crops in the USA.

\begin{tabular}{|l|l|}
\hline Type & Ha grown in 2014 \\
\hline Corn & $43,500,000$ \\
\hline Soybean & $32,300,000$ \\
\hline Cotton & $4,500,000$ \\
\hline Alfalfa & 862,000 \\
\hline Canola & 684,000 \\
\hline Sugar beet & 479,000 \\
\hline Papaya & 1,000 \\
\hline Squash & 1,000 \\
\hline
\end{tabular}

Source: Food and Agriculture Organization of the United Nations (FAO), Left $Y$ axis is for cotton and soybean.

Table 2: This is the table of the modified traits in soybean and cotton.

\begin{tabular}{|l|l|l|}
\hline Trait & Ticker symbol & First approved \\
\hline Herbicide tolerance & HT & 1993, Soybean \\
\hline Insect resistance & BT & 1995, Cotton \\
\hline
\end{tabular}

\section{- Results and Discussion \\ Yield:}

To employ linear regression, the data used in this study were derived from the dataset sources shown in Figures 1 and 2. Figure 1 plots the percentage of genetic engineering(GE)

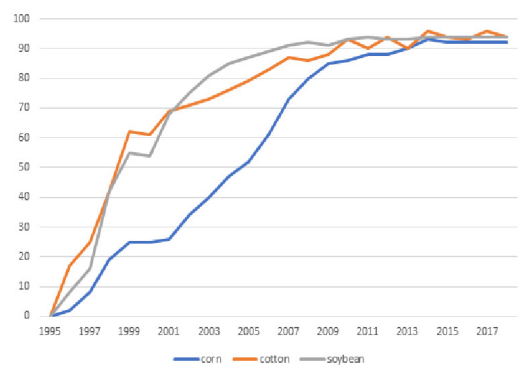

Figure 1: The adoption of genetic engineering (GE) crops was rapid in the USA from 1995 to 2018 . Y axis is GE crops percentage. $X$ axis is year.

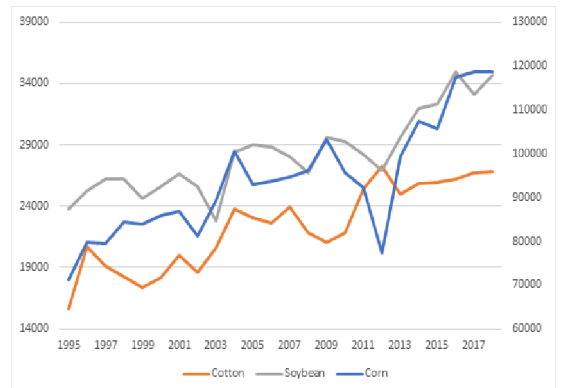

Figure 2: The yield in GE crops(kg/ha) increased remarkably from 1995 to 2018. Left $Y$ axis is for cotton and soybean. Right $Y$ axis is for corn. $Y$ axis is crop yield. $\mathrm{X}$ axis is year.
Source: Food and Agriculture Organization of the United Nations (FAO), Left $\mathrm{Y}$ axis is for cotton and soybean.

Figure 3 provides the empirical results of the regression analysis using the yield of soybean, cotton and corn as dependent variable against GMC percentage. Table 3 provides three parameters, correlation coefficient, slope of linear regression equation, and coefficient of determination, estimated from the regression analysis in three major field crops.

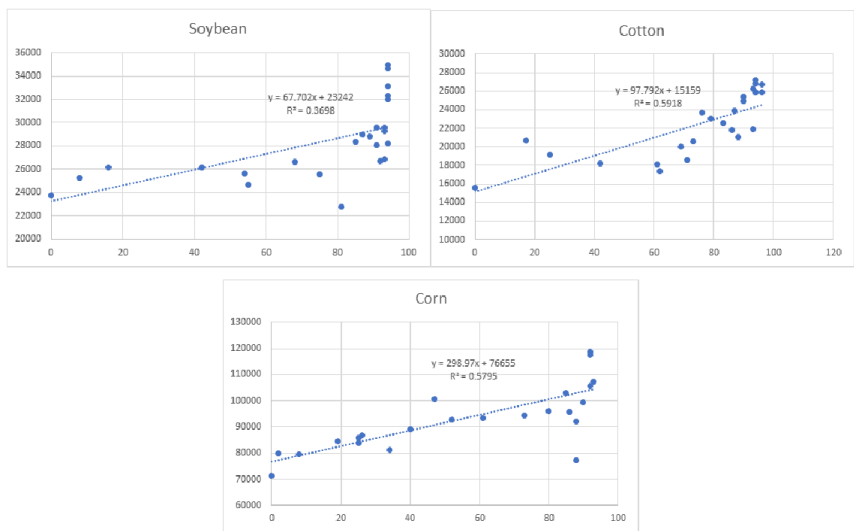

Figure 3: The $1 \%$ increase of GMC percentage improved crop yield (kg/ ha) by 67.702 (soybean), 97.792 (cotton), and 298.97 (corn). Y axis is crop yield. $\mathrm{X}$ axis is GMC percentage.

Table 3: This table shows the results for estimated parameters used to evaluate the relationship between yield and GMC percentage.

\begin{tabular}{|l|c|c|c} 
& $\begin{array}{c}\text { Correlation Coefficient } \\
(r)\end{array}$ & $\begin{array}{c}\text { Slope of Linear regression } \\
(a)\end{array}$ & $\begin{array}{c}\text { Coefficient of } \\
\text { Determination }\left(R^{2}\right)\end{array}$ \\
\hline Soybean & 0.76123 & 67.702 & 0.3698 \\
\hline Cotton & 0.769265 & 97.792 & 0.5918 \\
\hline Corn & 0.608088 & 298.97 & 0.5795 \\
\hline
\end{tabular}

As seen in Table 3, the percentage of GMCs and the yield have a clear correlation $(\mathrm{p}<0.05)$. If the GMC percentage is increased by $1 \%$, the yields of soybean, cotton, and corn will be improved by $67.702 \mathrm{~kg} / \mathrm{ha}, 97.792 \mathrm{~kg} / \mathrm{ha}$, and $298.97 \mathrm{~kg} /$ ha, respectively.

When analyzing the correlation between GMC percentage and yield, it should be ensured that other factors are controlled. Since the yield increases with the development of agricultural technology over time, it can be said that the introduction of GMC is related to the yield when the increase in yield over time is different before and after the introduction of GMC.

Figure 4 shows a graph of regression analysis indicating the yield as dependent variable against year before and after GMC use. The following formula shows how yield increase is calculated:

$$
\frac{a_{\text {after }}-a_{\text {before }}}{a_{\text {before }}}=\frac{1742.1-1107.6}{1107.6} \times 100(\%)=57.286 \%
$$

As technology advances, agricultural yields can be sufficiently high owing to other factors apart from GE. However, a yield increase of sufficiently high $57.286 \%$ before and after $\mathrm{GE}$ indicates a yield improvement through $\mathrm{GE}$ even though there may be an impact of technological advances. 


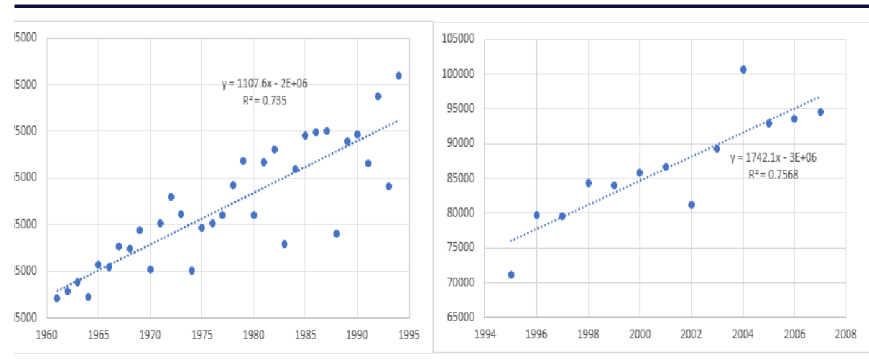

Figure 4: The yearly yield (kg/ha) increased by 1107.6 before GMC use and 1742.1 after GMC use. $\mathrm{Y}$ axis is crop yield. $\mathrm{X}$ axis is year.

Cost:

The decrease in chemical usage and increase in seed price were calculated to evaluate the cost reduction. To calculate the cost consumption in detail, the crop type is limited to corn. First, the decrease in the amount of chemicals used for corn cultivation was measured. The cost-benefit due to the chemicals was calculated. Then, the cost required to purchase GE seeds was also calculated. Finally, it was checked whether there is a cost-benefit, overall.

Source: USDA 2010 Corn, Upland Cotton, and Fall Potatoes - Released May 25, 2011.

(a)

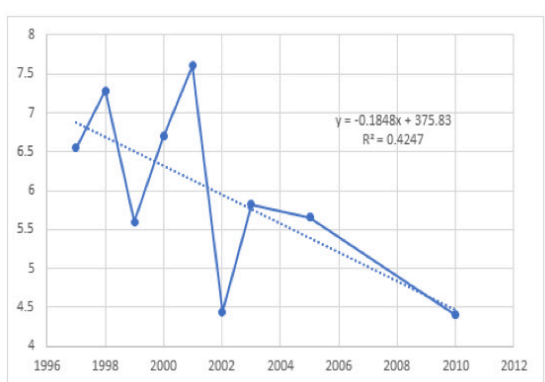

(b)

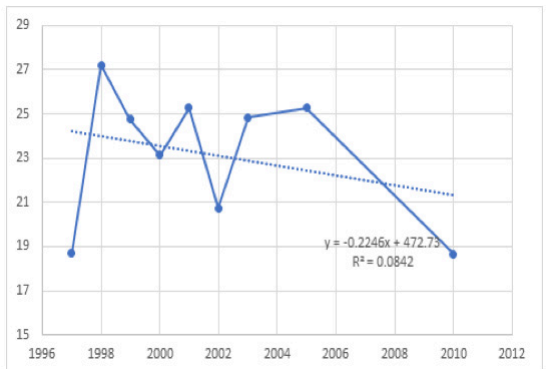

Figure 5: The yearly usage (lb/acre) of (a) insecticide and (b) herbicide (1996-2010) decreased by 0.1848 and 0.2246 , respectively. Y axis is chemical usage. $\mathrm{X}$ axis is year.

Figure 5 presents the outcome of the regression analysis of insecticide and herbicide usages against year during 19962010. The yearly usage of insecticide and herbicide decreased by $0.1848 \mathrm{lb} /$ acre and $0.2246 \mathrm{lb} / \mathrm{acre}$, respectively.

The following equations show the determination of per unit area of herbicide and insecticide used, which decreased over 15 years. The values were calculated using data presented in Table 4 (herbicides) and Table 5 (insecticides).

Herbicide: $-0.2246 \frac{L B}{\text { acre } \times \text { year }} \times 15$ year $\times 37 \frac{\text { dollar }}{\text { gal }} \times 0.12 \frac{\text { gal }}{l b}=-14.957$
Insecticide: $-0.1848 \frac{L B}{\text { acre } \times \text { year }} \times 15$ year $\times 16 \frac{\text { dollar }}{g a l} \times 0.12 \frac{\text { gal }}{l b}=-5.322$
Source: Nebraska's Top Weed Problems and Most Common Herbicides; JULY 26, 2018; Debalin Sarangi.

Table 4: The price for the three most commonly used herbicides in field corn.

\begin{tabular}{|l|l|l|}
\hline Rank & Field corn Herbicides & Price \\
\hline 1 & Glyphosate & $\$ 16 /$ gal \\
\hline 2 & Halex GT & $\$ 58 /$ gal \\
\hline 3 & Status & $\$ 4 /$ Ounce \\
\hline
\end{tabular}

Source: Courtesy of USDA Agricultural Chemicals and Production Technology: Pest Management.

Table 5: The price for the two most commonly used insecticides in field corn.

\begin{tabular}{|l|l|l|}
\hline Rank & Field corn Insecticide & Price \\
\hline 1 & Organophosphates & $\$ 17 /$ gal \\
\hline 2 & Pyrethroids & $\$ 15 /$ gal \\
\hline
\end{tabular}

Source: USDA Economic Research Service using data from USDA National Agricultural Statistics Service Agricultural Prices for various years.

Table 6: The cost for purchasing non-GE seed and GE seed.

\begin{tabular}{|l|l|l|}
\hline & Non-GE corn seed & GE corn seed \\
\hline Cost (dollar per bag) & 100 & 150 \\
\hline
\end{tabular}

The cost increase due to the use of GE seeds is as follows.

$$
(150-100) \frac{\text { dollar }}{\text { bag }} \times \frac{1 \text { bag }}{80,000 \mathrm{ker}} \times \frac{1300 \mathrm{ker}}{1 \text { pound }} \times \frac{1 \text { pound }}{15,000 \mathrm{seed}} \times \frac{34,000 \mathrm{seed}}{1 \text { arce }}=1.842 .
$$

$1.842-14.957-5.322=-18.437, \$ 18.437 /$ acre

The total cost-benefit is

Farmers cannot directly implement genetic modification technologies, so they have to buy genetically modified seeds from manufacturers (Table 6). GMC seeds cost approximately $\$ 50$ more than regular seeds. Therefore, farmers should be able to determine whether GMC use is profitable. Despite paying a premium for GMC seeds, farmers make a considerable cost saving on herbicides and insecticides, resulting in profits of approximately $\$ 18$ per unit acre.

\section{Managing Time:}

It is difficult to produce statistics directly for the working hours of farmers. Therefore, rather than directly calculating the working time, ${ }^{8}$ it will be determined whether the working time is improved by analyzing the factors affecting working time. The factors affecting working time depend on the GE function. Here, the study focused on the HT and BT presented previously and the gene modifying technique with other functions.

Weed control is an important challenge in crop production. If the time spent on weed control could be reduced, it could be concluded that the management time was reduced. Herbicide tolerance in crops can be created by genetic modification techniques that impart tolerance to particular herbicides allowing farmers to selectively kill weeds without harming their crops. Previously, it was found that an herbicide can remove weeds without affecting the crop; it is not necessary to do so for GMC. What is required is to select an herbicide that is effective against weeds and then create a GMC resistant to 
that herbicide. In other words, GMC can make the process of killing weeds more efficient and flexible.

The management of pests is also an important task in crop production. The management of pests directly affects the freshness and quality of the crop and is also an important part of the yield. Therefore, farmers must apply the appropriate pesticides every season to avoid damaging their crops. However, crops with BTs provide seasonal protection against many pests, reducing or eliminating pesticide use, allowing farmers to avoid crop losses due to pests, permitting more time to be spent on other farm management tasks.

In addition to $\mathrm{HT}$ and $\mathrm{BT}$, there are several other traits that are beneficial for crops. These traits that can be genetically modified to include extended shelf life, improved photosynthesis, improved nutritive value, stress resistance, and toxic reduction. Applying these, the farmer can allow the crop to solve at least one problem on its own. Thus, it is clear that GMC reduces farmer management time.

\section{- Conclusion}

An assessment of the relationship between yield increase and the rate at which GMCs were planted indicated that the use of GMCs significantly increases crop yield. In general, when planting rate of GMCs is increased by $1 \%$, yield improved by $100-300(\mathrm{~kg} / \mathrm{ha})$. However, before making any conclusions, it is necessary to examine whether the increase in yield interfered with factors other than GMCs. Other techniques besides GMC can improve the yield. Therefore, it is necessary to compare the rate of increase in yield before and after GMC to determine whether this is due to GMCs. The results show that yield improved by approximately $57 \%$ since the introduction of GMCs even though there may partly some impacts from technological advances.

The second research question concerns whether GMC brings cost-benefits. There are several costs associated with growing crops, but among these, the cost associated with GMC use was evaluated. GMCs have cost benefits related to herbicides and pesticides, but a premium must be paid to GMC companies for the GMC seed. Therefore, the difference between the two should be used to calculate the actual cost savings. The present study revealed that GMC provides farmers with a gain of $\$ 18.43$ per unit area.

The third research question was whether GMC reduces farm management time. Since it is difficult to access statistics for farm management time directly, we qualitatively checked whether GMCs affect farm management time by analyzing its functions. Both HT and BT were judged to reduce management time as they affect weeding and pest removal, which are important in crop cultivation. In addition, GMCs with other functions have been found to play a role in removing one or more farm management concerns by farmers.

The study has shown that GMC is, in many ways, a relief for farmers. It was confirmed that there were improvements in many areas, such as yield, cost, and time. Through this study, a methodology for calculating the effect of technology on food was proposed. The GMC production was analyzed using this method.
This study investigated only HT and BT, corn, soybean, and cotton. Future studies may include GMCs with other features in the market. This study provides a methodology for analyz ing other crops in the future. More, usage of non-GMC data as control will improve the study with better and stronger results.

This study also analyzed only the net function of the GMC. It will be necessary to analyze the negative aspects of GMCs (e.g., allergies, environmental problems, etc.) and evaluate whether it has a good effect on society.

\section{- References}

1. Fernandez-Cornejo, J.; McBride, W.D. Adoption of bioengineered crops. Agricultural Economic Report AER-810, Economic Research Service/USDA, 2002, http://hdl.handle.net/1805/767.

2. Fernandez-Cornejo, J. The seed industry in U.S. agriculture: an exploration of data and information on crop seed markets, regulation, industry structure, and research and development. AIB-786, Economic Research Service/USDA, 2004. https:// www.researchgate.net/publication/23516844.

3. Green, J. M. The benefits of herbicide-resistant crops. Pest Manag. Sci., 2012, 68(10), 1323-1331.

4. National Research Council. The impact of genetically engineered crops on farm sustainability in the United States, chapter 3 farmlevel economic impacts. Washington D. C.:The National Academies Press, 2010, www.nap.edu/read/12804/chapter/5\#137.

5. James, C. Global status of commercialized biotech/GM crops: 2014, ISAAA Brief 49, ISAAA, 2014, www.isaaa.org/resources/ publications/briefs/52/download/isaaa-brief-52-2016.pdf.

6. Fernandez-Cornejo, J.; Wechsler, S.; Livingston, M.; Mitchell, L. Genetically engineered crops in the United States. Economic Research Paper ERP-162, Economic Research Service/USDA, 2014, www.ers.usda.gov/webdocs/publications/45179/43668_ err162.pdf? $=6903.2$.

7. Fernandez-Cornejo, J.; Casewell, M. The first decade of genetically engineered crops in the United States. Economic Information Bulletin EIB-11, Economic Research Service/USDA, 2006, www. ers.usda.gov/webdocs/publications/43731/13396_eib11_1_. pdf?v $=41746$

8. Singh, P. N.; Sebatè, J.; Fraser, G. E. Does low meat consumption increase life expectancy in humans? Am J. Clin. Nutr., 2003, 78(3), 526-532, https://academic.oup.com/ajcn/arti cle/78/3/526S/4689992.

\section{- Author}

Do Hoon Kim is currently a senior at Northfield Mount Hermon School. He has conducted a senior capstone project on community supported agriculture. His main academic interest is food security and he is planning to major in Environmental Studies. 